In the 1 st experiment, gilts ( $\mathrm{LW} \times \mathrm{LR}$ ) belonging to a farm located $15 \mathrm{~km}$ away were exposed to the boar immediately after their arrival in the experimental farm. In the second one, only part of the gilts (LW) were subjected to the male effect (group A), while the others $(\mathrm{LW} \times \mathrm{LR})$ were subjected to transport stress and the following day to boar introduction (group B). In the latter experiment the adrenal activity was inhibited by a dexamethasone injection in half the females the day before, the very same day and the day after transport and boar introduction. In the first two experiments, ovaries were examined by endoscopy the day of arrival in the experimental farm or the day before boar introduction, then 7 to 14 days later by endoscopy or after slaughter. In females of the second experiment, blood samples were collected on the day of transport and during the first eight hours following boar introduction. The plasma levels of cortisol, prolactin and LH were measured in these samples.

Examination of ovaries and uterus showed two stages of maturity before puberty : "impuberty» characterised by numerous follicles $(3$ to $5 \mathrm{~mm}$ ) and a pale and little developed uterus and "prebuberty» characterised by some follicles (4 to $8 \mathrm{~mm}$ ) and a well irrigated and developed uterus. However, induction of puberty depended more on the nature of the stimulus used than on the maturity stage as ovulation occurred in 76 and 29 p. 100 of the gilts respectively according as the boar introduction followed or not herd changes. But there was no precise relationship with the initial stage of the genital tract. The lower efficiency of the male effect was probably due to an insufficient stimulation of adrenal glands and pituitary as shown by lower plasma levels of cortisol, LH and prolactin. The dexamethasone treatment retarded by about 70 hours the onset of first oestrus without inhibiting it.

\title{
Possibilities and limits of using boars in natural mating
}

\author{
R. NOWAK *, M. PAQUIGNON**, J.P. SIGNORET * \\ * I.N.R.A., Station de Physiologie de la Reproduction, \\ Nouzilly, 37380 Monnaie \\ ** Institut Technique du Porc, 149, rue de Bercy, 75595 Paris Cedex 12
}

Sperm production of boars subjected to an intensive collection rhythm was compared to that resulting from natural mating. Sow fertility was tested after natural mating at different ejaculation rhythms.

Each boar was collected 1,2,3, and 4 times per day for 5 days after a sexual rest of 2 weeks between each series of ejaculations. Some sows were slaughtered immediately after mating for measuring sperm deposited into the uterus. Fertility was tested in sows slaughtered 30-35 days after mating.

The increased collection frequency considerably reduced the sexual activity of boars as well as the number of spermatozoa per ejaculate.

When collection was made once a day, sperm production per ejaculate decreased linearly from the 1 st to the 5 th day of collection. When collections were made 2,3 and 4 times a day the production decrease observed on day 1 was followed by a more steady production. From the $3 \mathrm{rd}$ day, sperm production did not exceed $10 \times 10^{9}$ for 2 collections and rarely exceeded $5 \times 10^{9}$ for 3 and 4 collections.

The number of cjaculates including less than $3 \times 10^{\mathrm{a}} \mathrm{spz}$ regularly augmented with an increased ejaculation rhythm.

There was no sperm production difference between collection and mating conditions. During mating, spermatozoa losses due to a reflux from the female genital tract may reach 50 p. 100 of the sperm produced.

In our experimental conditions, fertility decreased from 91.6 to $58.3 \mathrm{p}$. 100 when mating frequency increased from 1 to 4 per day. 